\title{
PERSPECTIVAS ATUAIS DA EDUCAÇÃO
}

\author{
Moacir Gadotti \\ Professor da Universidade de São Paulo e Diretor do Instituto Paulo Freire. \\ Autor, dentre outras obras, de Perspectivas atuais da educação.
}

\begin{abstract}
Resumo: O conhecimento tem presença garantida em qualquer projeção que se faça do futuro. Por isso há um consenso de que o desenvolvimento de um país está condicionado à qualidade da sua educação. Nesse contexto, as perspectivas para a educação são otimistas. A pergunta que se faz é: qual educação, qual escola, qual aluno, qual professor? Este artigo busca compreender a educação no contexto da globalização e da era da informação, tira conseqüências desse processo e aponta o que poderá permanecer da "velha" educação, indicando algumas categorias fundantes da educação do futuro.

Palavras-chave: política educacional; globalização e ensino; educação e sociedade.
\end{abstract}

$\mathrm{N}$ as últimas duas décadas do século $\mathrm{XX}$ assistiuse a grandes mudanças tanto no campo socioeconômico e político quanto no da cultura, da ciência e da tecnologia. Ocorreram grandes movimentos sociais, como aqueles no leste europeu, no final dos anos 80, culminando com a queda do Muro de Berlim. Ainda não se tem idéia clara do que deverá representar, para todos nós, a globalização capitalista da economia, das comunicações e da cultura. As transformações tecnológicas tornaram possível o surgimento da era da informação.

É um tempo de expectativas, de perplexidade e da crise de concepções e paradigmas não apenas porque iniciase um novo milênio - época de balanço e de reflexão, época em que o imaginário parece ter um peso maior. $\mathrm{O}$ ano 2000 exerceu um fascínio muito grande em muitas pessoas. Paulo Freire dizia que queria chegar ao ano 2000 (acabou falecendo três anos antes). É um momento novo e rico de possibilidades. Por isso, não se pode falar do futuro da educação sem certa dose de cautela. É com essa cautela que serão examinadas, neste artigo, algumas das perspectivas atuais da teoria e da prática da educação, apoiando-se naqueles educadores e filósofos que tentaram, em meio a essa perplexidade, apesar de tudo, apontar algum caminho para o futuro. A perplexidade e a crise de paradigmas não podem se constituir num álibi para o imobilismo.

No início deste século, H. G. Wells dizia que "a História da Humanidade é cada vez mais a disputa de uma cor- rida entre a educação e a catástrofe". A julgar pelas duas grandes guerras que marcaram a "História da Humanidade", na primeira metade do século XX, a catástrofe venceu. No início dos anos 50, dizia-se que só havia uma alternativa: "socialismo ou barbárie" (Cornelius Castoriadis), mas chegou-se ao final do século com a derrocada do socialismo burocrático de tipo soviético e enfraquecimento da ética socialista. E mais: pela primeira vez na história da humanidade, não por efeito de armas nucleares, mas pelo descontrole da produção industrial, pode-se destruir toda a vida do planeta. Mais do que a solidariedade, estamos vendo crescer a competitividade. Venceu a barbárie, de novo? Qual o papel da educação neste novo contexto político? Qual é o papel da educação na era da informação? Que perspectivas podemos apontar para a educação nesse início do Terceiro Milênio? Para onde vamos?

Para iniciar, verifica-se o significado da palavra "perspectiva". A palavra "perspectiva" vem do latim tardio "perspectivus", que deriva de dois verbos: perspecto, que significa "olhar até o fim, examinar atentamente"; e perspicio, que significa "olhar através, ver bem, olhar atentamente, examinar com cuidado, reconhecer claramente" (Dicionário Escolar Latino-Português, de Ernesto Faria). A palavra "perspectiva" é rica de significações. Segundo o Dicionário de filosofia, do filósofo italiano Nicola Abbagnano, perspectiva seria "uma antecipação qualquer do futuro: projeto, esperança, ideal, ilusão, utopia. O ter- 
mo exprime o mesmo conceito de possibilidade mas de um ponto de vista mais genérico e que menos compromete, dado que podem aparecer como perspectivas coisas que não têm suficiente consistência para serem possibilidades autênticas". Para o Dicionário Aurélio, muito conhecido entre nós, brasileiros, perspectiva é a "arte de representar os objetos sobre um plano tais como se apresentam à vista; pintura que representa paisagens e edifícios a distância; aspecto dos objetos vistos de uma certa distância; panorama; aparência, aspecto; aspecto sob o qual uma coisa se apresenta, ponto de vista; expectativa, esperança". Perspectiva significa ao mesmo tempo enfoque, quando se fala, por exemplo, em perspectiva política, e possibilidade, crença em acontecimentos considerados prováveis e bons. Falar em perspectivas é falar de esperança no futuro.

Hoje muitos educadores, perplexos diante das rápidas mudanças na sociedade, na tecnologia e na economia, perguntam-se sobre o futuro de sua profissão, alguns com medo de perdê-la sem saber o que devem fazer. Então, aparecem, no pensamento educacional, todas as palavras citadas por Abbagnano e Aurélio: "projeto" político-pedagógico, pedagogia da "esperança", "ideal” pedagógico, "ilusão" e "utopia" pedagógica, o futuro como "possibilidade". Fala-se muito hoje em "cenários" possíveis para a educação, portanto, em "panoramas", representação de "paisagens". Para se desenhar uma perspectiva é preciso "distanciamento". É sempre um "ponto de vista". Todas essas palavras entre aspas indicam uma certa direção ou, pelo menos, um horizonte em direção ao qual se caminha ou se pode caminhar. Elas designam "expectativas" e anseios que podem ser captados, capturados, sistematizados e colocados em evidência.

\section{UM PASSADO SEMPRE PRESENTE}

A virada do milênio é razão oportuna para um balanço sobre práticas e teorias que atravessaram os tempos. Falar de "perspectivas atuais da educação" é também falar, discutir, identificar o "espírito" presente no campo das idéias, dos valores e das práticas educacionais que as perpassa, marcando o passado, caracterizando o presente e abrindo possibilidades para o futuro. Algumas perspectivas teóricas que orientaram muitas práticas poderão desaparecer, e outras permanecerão em sua essência. Quais teorias e práticas fixaram-se no ethos educacional, criaram raízes, atravessaram o milênio e estão presentes hoje? Para entender o futuro é preciso revisitar o passado. No cenário da educação atual, podem ser destacados alguns marcos, algumas pegadas, que persistem e poderão persistir na educação do futuro.

\section{Educação Tradicional}

Enraizada na sociedade de classes escravista da Idade Antiga, destinada a uma pequena minoria, a educação tradicional iniciou seu declínio já no movimento renascentista, mas ela sobrevive até hoje, apesar da extensão média da escolaridade trazida pela educação burguesa. A educação nova, que surge de forma mais clara a partir da obra de Rousseau, desenvolveu-se nesses últimos dois séculos e trouxe consigo numerosas conquistas, sobretudo no campo das ciências da educação e das metodologias de ensino. O conceito de "aprender fazendo" de John Dewey e as técnicas Freinet, por exemplo, são aquisições definitivas na história da pedagogia. Tanto a concepção tradicional de educação quanto a nova, amplamente consolidadas, terão um lugar garantido na educação do futuro.

A educação tradicional e a nova têm em comum a concepção da educação como processo de desenvolvimento individual. Todavia, o traço mais original da educação desse século é o deslocamento de enfoque do individual para o social, para o político e para o ideológico. A pedagogia institucional é um exemplo disso. A experiência de mais de meio século de educação nos países socialistas também o testemunha. A educação, no século XX, tornou-se permanente e social. É verdade, existem ainda muitos desníveis entre regiões e países, entre o Norte e o Sul, entre países periféricos e hegemônicos, entre países globalizadores e globalizados. Entretanto, há idéias universalmente difundidas, entre elas a de que não há idade para se educar, de que a educação se estende pela vida e que ela não é neutra.

\section{Educação Internacionalizada}

No início da segunda metade deste século, educadores e políticos imaginaram uma educação internacionaliza$d a$, confiada a uma grande organização, a Unesco. Os países altamente desenvolvidos já haviam universalizado o ensino fundamental e eliminado o analfabetismo. Os sistemas nacionais de educação trouxeram um grande impulso, desde o século passado, possibilitando numerosos planos de educação, que diminuíram custos e elevaram os benefícios. A tese de uma educação internacional já existia deste 1899, quando foi fundado, em Bruxelas, o Bureau In- 
ternacional de Novas Escolas, por iniciativa do educador Adolphe Ferrière. Como resultado, tem-se hoje uma grande uniformidade nos sistemas de ensino. Pode-se dizer que hoje todos os sistemas educacionais contam com uma estrutura básica muito parecida. No final do século XX, o fenômeno da globalização deu novo impulso à idéia de uma educação igual para todos, agora não como princípio de justiça social, mas apenas como parâmetro curricular comum.

\section{Novas Tecnologias}

As conseqüências da evolução das novas tecnologias, centradas na comunicação de massa, na difusão do conhecimento, ainda não se fizeram sentir plenamente no ensino - como previra McLuhan já em 1969 -, pelo menos na maioria das nações, mas a aprendizagem a distância, sobretudo a baseada na Internet, parece ser a grande novidade educacional neste início de novo milênio. A educação opera com a linguagem escrita e a nossa cultura atual dominante vive impregnada por uma nova linguagem, a da televisão e a da informática, particularmente a linguagem da Internet. A cultura do papel representa talvez o maior obstáculo ao uso intensivo da Internet, em particular da educação a distância com base na Internet. Por isso, os jovens que ainda não internalizaram inteiramente essa cultura adaptam-se com mais facilidade do que os adultos ao uso do computador. Eles já estão nascendo com essa nova cultura, a cultura digital.

Os sistemas educacionais ainda não conseguiram avaliar suficientemente o impacto da comunicação audiovisual e da informática, seja para informar, seja para bitolar ou controlar as mentes. Ainda trabalha-se muito com recursos tradicionais que não têm apelo para as crianças e jovens. Os que defendem a informatização da educação sustentam que é preciso mudar profundamente os métodos de ensino para reservar ao cérebro humano o que lhe é peculiar, a capacidade de pensar, em vez de desenvolver a memória. Para ele, a função da escola será, cada vez mais, a de ensinar a pensar criticamente. Para isso é preciso dominar mais metodologias e linguagens, inclusive a linguagem eletrônica.

\section{Paradigmas Holonômicos}

Entre as novas teorias surgidas nesses últimos anos, despertaram interesse dos educadores os chamados paradigmas holonômicos, ainda pouco consistentes. Complexidade e holismo são palavras cada vez mais ouvidas nos debates educacionais. Nesta perspectiva, pode-se incluir as reflexões de Edgar Morin, que critica a razão produtivista e a racionalização modernas, propondo uma lógica do vivente. Esses paradigmas sustentam um princípio unificador do saber, do conhecimento, em torno do ser humano, valorizando o seu cotidiano, o seu vivido, o pessoal, a singularidade, o entorno, o acaso e outras categorias como: decisão, projeto, ruído, ambigüidade, finitude, escolha, síntese, vínculo e totalidade.

Essas seriam algumas das categorias dos paradigmas chamados holonômicos. Etimologicamente, holos, em grego, significa todo e os novos paradigmas procuram centrarse na totalidade. Mais do que a ideologia, seria a utopia que teria essa força para resgatar a totalidade do real, totalidade perdida. Para os defensores desses novos paradigmas, os paradigmas clássicos - identificados no positivismo e no marxismo - seriam marcados pela ideologia e lidariam com categorias redutoras da totalidade. Ao contrário, os paradigmas holonômicos pretendem restaurar a totalidade do sujeito, valorizando a sua iniciativa e a sua criatividade, valorizando o micro, a complementaridade, a convergência e a complexidade. Para eles, os paradigmas clássicos sustentam o sonho milenarista de uma sociedade plena, sem arestas, em que nada perturbaria um consenso sem fricções. Ao aceitar como fundamento da educação uma antropologia que concebe o homem como um ser essencialmente contraditorial, os paradigmas holonômicos pretendem manter, sem pretender superar, todos os elementos da complexidade da vida.

Os holistas sustentam que o imaginário e a utopia são os grandes fatores instituintes da sociedade e recusam uma ordem que aniquila o desejo, a paixão, o olhar e a escuta. Os enfoques clássicos, segundo eles, banalizam essas dimensões da vida porque sobrevalorizam o macro-estrutural, o sistema, em que tudo é função ou efeito das superestruturas socioeconômicas ou epistêmicas, lingüísticas e psíquicas. Para os novos paradigmas, a história é essencialmente possibilidade, em que o que vale é o imaginário (Gilbert Durand, Cornelius Castoriadis), o projeto. Existem tantos mundos quanto nossa capacidade de imaginar. Para eles, "a imaginação está no poder", como queriam os estudantes em maio de 1968.

Na verdade, essas categorias não são novas na teoria da educação, mas hoje são lidas e analisadas com mais simpatia do que no passado. Sob diversas formas e com diferentes significados, essas categorias são encontradas em muitos intelectuais, filósofos e educadores, de ontem e de hoje: o "sentido do outro", a "curiosidade" (Paulo Freire), a "tolerân- 
cia" (Karl Jaspers), a "estrutura de acolhida" (Paul Ricoeur), o "diálogo" (Martin Buber), a "autogestão" (Celestin Freinet, Michel Lobrot), a "desordem" (Edgar Morin), a "ação comunicativa", o "mundo vivido" (Jürgen Habermas), a "radicalidade" (Agnes Heller), a "empatia" (Carl Rogers), a “questão de gênero" (Moema Viezzer, Nelly Stromquist), o "cuidado" (Leonardo Boff), a "esperança” (Ernest Bloch), a "alegria" (Georges Snyders), a unidade do homem contra as "unidimensionalizações" (Herbert Marcuse), etc.

Evidentemente, nem todos esses autores aceitariam enquadrar-se nos paradigmas holonômicos. Todas as classificações e tipologias, no campo das idéias, são necessariamente reducionistas. Não se pode negar as divergências existentes entre eles. Contudo, as categorias apontadas anteriormente indicam uma certa tendência, ou melhor, uma perspectiva da educação. Os que sustentam os paradigmas holonômicos procuram buscar na unidade dos contrários e na cultura contemporânea um sinal dos tempos, uma direção do futuro, que eles chamam de pedagogia da unidade.

\section{Educação Popular}

O paradigma da educação popular, inspirado originalmente no trabalho de Paulo Freire nos anos 60, encontrava na conscientização sua categoria fundamental. A prática e a reflexão sobre a prática levaram a incorporar outra categoria não menos importante: a da organização. Afinal, não basta estar consciente, é preciso organizar-se para poder transformar. Nos últimos anos, os educadores que permaneceram fiéis aos princípios da educação popular atuaram principalmente em duas direções: na educação pública popular - no espaço conquistado no interior do Estado -; e na educação popular comunitária e na educação ambiental ou sustentável, predominantemente nãogovernamentais. Durante os regimes autoritários da América Latina, a educação popular manteve sua unidade, combatendo as ditaduras e apresentando projetos "alternativos". Com as conquistas democráticas, ocorreu com a educação popular uma grande fragmentação em dois sentidos: de um lado ela ganhou uma nova vitalidade no interior do Estado, diluindo-se em suas políticas públicas; e, de outro, continuou como educação não-formal, dispersando-se em milhares de pequenas experiências. Perdeu em unidade, ganhou em diversidade e conseguiu atravessar numerosas fronteiras. Hoje ela incorporou-se ao pensamento pedagógico universal e orienta a atuação de muitos educadores espalhados pelo mundo, como o tes- temunha o Fórum Paulo Freire, que se realiza de dois em dois anos, reunindo educadores de muitos países.

As práticas de educação popular também constituemse em mecanismos de democratização, em que se refletem os valores de solidariedade e de reciprocidade e novas formas alternativas de produção e de consumo, sobretudo as práticas de educação popular comunitária, muitas delas voluntárias. O Terceiro Setor está crescendo não apenas como alternativa entre o Estado burocrático e o mercado insolidário, mas também como espaço de novas vivências sociais e políticas hoje consolidadas com as organizações não-governamentais (ONGs) e as organizações de base comunitária (OBCs). Este está sendo hoje o campo mais fértil da educação popular.

Diante desse quadro, a educação popular, como modelo teórico reconceituado, tem oferecido grandes alternativas. Dentre elas, está a reforma dos sistemas de escolarização pública. A vinculação da educação popular com o poder local e a economia popular abre, também, novas e inéditas possibilidades para a prática da educação. O modelo teórico da educação popular, elaborado na reflexão sobre a prática da educação durante várias décadas, tornou-se, sem dúvida, uma das grandes contribuições da América Latina à teoria e à prática educativa em âmbito internacional. A noção de aprender a partir do conhecimento do sujeito, a noção de ensinar a partir de palavras e temas geradores, a educação como ato de conhecimento e de transformação social e a politicidade da educação são apenas alguns dos legados da educação popular à pedagogia crítica universal.

\section{Universalização da Educação Básica e Novas Matrizes Teóricas}

Neste começo de um novo milênio, a educação apresenta-se numa dupla encruzilhada: de um lado, o desempenho do sistema escolar não tem dado conta da universalização da educação básica de qualidade; de outro, as novas matrizes teóricas não apresentam ainda a consistência global necessária para indicar caminhos realmente seguros numa época de profundas e rápidas transformações. Essa é uma das preocupações do Instituto Paulo Freire, buscando, a partir do legado de Paulo Freire, consolidar o seu "Projeto da Escola Cidadã”, como resposta à crise de paradigmas. A concepção teórica e as práticas desenvolvidas a partir do conceito de Escola Cidadã podem constituir-se numa alternativa viável, de um lado, ao projeto neoliberal de educação, amplamente hegemônico, baseado na ética do mercado, e, de ou- 
tro lado, à teoria e à prática de uma educação burocrática, sustentada na "estadolatria" (Antonio Gramsci). É uma escola que busca fortalecer autonomamente o seu projeto político-pedagógico, relacionando-se dialeticamente - não mecânica e subordinadamente - com o mercado, o Estado e a sociedade. Ela visa formar o cidadão para controlar o mercado e o Estado, sendo, ao mesmo tempo, pública quanto ao seu destino - isto é, para todos - estatal quanto ao financiamento e democrática e comunitária quanto à sua gestão.

Seja qual for a perspectiva que a educação contemporânea tomar, uma educação voltada para o futuro será sempre uma educação contestadora, superadora dos limites impostos pelo Estado e pelo mercado, portanto, uma educação muito mais voltada para a transformação social do que para a transmissão cultural. Por isso, acredita-se que a pedagogia da práxis, como uma pedagogia transformadora, em suas várias manifestações, pode oferecer um referencial geral mais seguro do que as pedagogias centradas na transmissão cultural, neste momento de perplexidade.

\section{SOCIEDADE DA INFORMAÇÃO E EDUCAÇÃO}

Costuma-se definir nossa era como a era do conhecimento. Se for pela importância dada hoje ao conhecimento, em todos os setores, pode-se dizer que se vive mesmo na era do conhecimento, na sociedade do conhecimento, sobretudo em consequiência da informatização e do processo de globalização das telecomunicações a ela associado. Pode ser que, de fato, já se tenha ingressado na era do conhecimento, mesmo admitindo que grandes massas da população estejam excluídas dele. Todavia, o que se constata é a predominância da difusão de dados e informações e não de conhecimentos. Isso está sendo possível graças às novas tecnologias que estocam o conhecimento, de forma prática e acessível, em gigantescos volumes de informações, que são armazenadas inteligentemente, permitindo a pesquisa e o acesso de maneira muito simples, amigável e flexível. É o que já acontece com a Internet: para ser "usuário", basta dispor de uma linha telefônica e um computador. "Usuário" não significa aqui apenas receptor de informações, mas também emissor de informações. Pela Internet, a partir de qualquer sala de aula do planeta, pode-se acessar inúmeras bibliotecas em muitas partes do mundo. As novas tecnologias permitem acessar conhecimentos transmitidos não apenas por palavras, mas também por imagens, sons, fotos, vídeos (hipermídia), etc. Nos últimos anos, a informação deixou de ser uma área ou especialidade para se tornar uma dimensão de tudo, transformando profundamente a forma como a sociedade se organiza. Pode-se dizer que está em andamento uma Revolução da Informação, como ocorreram no passado a Revolução Agrícola e a Revolução Industrial.

Ladislau Dowbor (1998), após descrever as facilidades que as novas tecnologias oferecem ao professor, se pergunta: o que eu tenho a ver com tudo isso, se na minha escola não tem nem biblioteca e com o meu salário eu não posso comprar um computador? Ele mesmo responde que será preciso trabalhar em dois tempos: o tempo do passado e o tempo do futuro. Fazer tudo hoje para superar as condições do atraso e, ao mesmo tempo, criar as condições para aproveitar amanhã as possibilidades das novas tecnologias.

As novas tecnologias criaram novos espaços do conhecimento. Agora, além da escola, também a empresa, o espaço domiciliar e o espaço social tornaram-se educativos. Cada dia mais pessoas estudam em casa, pois podem, de casa, acessar o ciberespaço da formação e da aprendizagem a distância, buscar "fora" - a informação disponível nas redes de computadores interligados - serviços que respondem às suas demandas de conhecimento. Por outro lado, a sociedade civil (ONGs, associações, sindicatos, igrejas, etc.) está se fortalecendo não apenas como espaço de trabalho, em muitos casos, voluntário, mas também como espaço de difusão de conhecimentos e de formação continuada. É um espaço potencializado pelas novas tecnologias, inovando constantemente nas metodologias. Novas oportunidades parecem abrir-se para os educadores. Esses espaços de formação têm tudo para permitir maior democratização da informação e do conhecimento, portanto, menos distorção e menos manipulação, menos controle e mais liberdade. É uma questão de tempo, de políticas públicas adequadas e de iniciativa da sociedade. A tecnologia não basta. É preciso a participação mais intensa e organizada da sociedade. $\mathrm{O}$ acesso à informação não é apenas um direito. É um direito fundamental, um direito primário, o primeiro de todos os direitos, pois sem ele não se tem acesso aos outros direitos.

$\mathrm{Na}$ formação continuada necessita-se de maior integração entre os espaços sociais (domiciliar, escolar, empresarial, etc.), visando equipar o aluno para viver melhor na sociedade do conhecimento. Como previa Herbert McLuhan, o planeta tornou-se a nossa sala de aula e o nosso endereço. O ciberespaço não está em lugar nenhum, pois está em todo o lugar o tempo todo. Estar num lugar significaria estar determinado pelo tempo (hoje, ontem, amanhã). No ciberespaço, a informação está sempre e per- 
manentemente presente e em renovação constante. $\mathrm{O}$ ciberespaço rompeu com a idéia de tempo próprio para a aprendizagem. Não há tempo e espaço próprios para a aprendizagem. Como ele está todo o tempo em todo lugar, o espaço da aprendizagem é aqui - em qualquer lugare o tempo de aprender é hoje e sempre. A sociedade do conhecimento se traduz por redes, "teias" (Ivan Illich), "árvores do conhecimento" (Humberto Maturana), sem hierarquias, em unidades dinâmicas e criativas, favorecendo a conectividade, o intercâmbio, consultas entre instituições e pessoas, articulação, contatos e vínculos, interatividade. A conectividade é a principal característica da Internet.

O conhecimento é o grande capital da humanidade. Não é apenas o capital da transnacional que precisa dele para a inovação tecnológica. Ele é básico para a sobrevivência de todos e, por isso, não deve ser vendido ou comprado, mas sim disponibilizado a todos. Esta é a função de instituições que se dedicam ao conhecimento apoiado nos avanços tecnológicos. Espera-se que a educação do futuro seja mais democrática, menos excludente. Essa é ao mesmo tempo nossa causa e nosso desafio. Infelizmente, diante da falta de políticas públicas no setor, acabaram surgindo "indústrias do conhecimento", prejudicando uma possível visão humanista, tornando-o instrumento de lucro e de poder econômico.

A educação, em particular a educação a distância, é um bem coletivo e, por isso, não deve ser regulada pelo jogo do mercado, nem pelos interesses políticos ou pelo furor legiferante de regulamentar, credenciar, autorizar, reconhecer, avaliar, etc. de muitos tecnoburocratas. Quem deve decidir sobre a qualidade dos seus certificados não é nem o Estado e nem o mercado, mas sim a sociedade e o sujeito aprendente. Na era da informação generalizada, existirá ainda necessidade de diplomas?

O que cabe à escola na sociedade informacional? Cabe a ela organizar um movimento global de renovação cultural, aproveitando-se de toda essa riqueza de informações. Hoje é a empresa que está assumindo esse papel inovador. A escola não pode ficar a reboque das inovações tecnológicas. Ela precisa ser um centro de inovação. Temos uma tradição de dar pouca importância à educação tecnológica, a qual deveria começar já na educação infantil.

$\mathrm{Na}$ sociedade da informação, a escola deve servir de bússola para navegar nesse mar do conhecimento, superando a visão utilitarista de só oferecer informações "úteis" para a competitividade, para obter resultados. Deve oferecer uma formação geral na direção de uma educação integral. O que significa servir de bússola? Significa ori- entar criticamente, sobretudo as crianças e jovens, na busca de uma informação que os faça crescer e não embrutecer.

Hoje vale tudo para aprender. Isso vai além da "reciclagem" e da atualização de conhecimentos e muito mais além da "assimilação" de conhecimentos. A sociedade do conhecimento possui múltiplas oportunidades de aprendizagem: parcerias entre o público e o privado (família, empresa, associações, etc.); avaliações permanentes; debate público; autonomia da escola; generalização da inovação. As conseqüências para a escola e para a educação em geral são enormes: ensinar a pensar; saber comunicar-se; saber pesquisar; ter raciocínio lógico; fazer sínteses e elaborações teóricas; saber organizar o seu próprio trabalho; ter disciplina para o trabalho; ser independente e autônomo; saber articular o conhecimento com a prática; ser aprendiz autônomo e a distância.

Neste contexto de impregnação do conhecimento, cabe à escola: amar o conhecimento como espaço de realização humana, de alegria e de contentamento cultural; selecionar e rever criticamente a informação; formular hipóteses; ser criativa e inventiva (inovar); ser provocadora de mensagens e não pura receptora; produzir, construir e reconstruir conhecimento elaborado. E mais: numa perspectiva emancipadora da educação, a escola tem que fazer tudo isso em favor dos excluídos, não discriminando o pobre. Ela não pode distribuir poder, mas pode construir e reconstruir conhecimentos, saber, que é poder. Numa perspectiva emancipadora da educação, a tecnologia contribui muito pouco para a emancipação dos excluídos se não for associada ao exercício da cidadania.

Como diz Ladislau Dowbor (1998:259), a escola deixará de ser "lecionadora" para ser "gestora do conhecimento". Segundo o autor, "pela primeira vez a educação tem a possibilidade de ser determinante sobre o desenvolvimento". A educação tornou-se estratégica para o desenvolvimento, mas, para isso, não basta "modernizá-la", como querem alguns. Será preciso transformá-la profundamente.

A escola precisa ter projeto, precisa de dados, precisa fazer sua própria inovação, planejar-se a médio e a longo prazos, fazer sua própria reestruturação curricular, elaborar seus parâmetros curriculares, enfim, ser cidadã. As mudanças que vêm de dentro das escolas são mais duradouras. Da sua capacidade de inovar, registrar, sistematizar a sua prática/experiência, dependerá o seu futuro. Nesse contexto, o educador é um mediador do conhecimento, diante do aluno que é o sujeito da sua própria formação. Ele precisa construir conhecimento a partir do que faz e, para isso, também precisa ser curioso, buscar sentido para 
o que faz e apontar novos sentidos para o que fazer dos seus alunos.

Em geral, temos a tendência de desvalorizar o que fazemos na escola e de buscar receitas fora dela quando é ela mesma que deveria governar-se. É dever dela ser cidadã e desenvolver na sociedade a capacidade de governar e controlar o desenvolvimento econômico e o mercado. A cidadania precisa controlar o Estado e o mercado, verdadeira alternativa ao capitalismo neoliberal e ao socialismo burocrático e autoritário. A escola precisa dar o exemplo, ousar construir o futuro. Inovar é mais importante do que reproduzir com qualidade o que existe. A matéria-prima da escola é sua visão do futuro.

A escola está desafiada a mudar a lógica da construção do conhecimento, pois a aprendizagem agora ocupa toda a nossa vida. E porque passamos todo o tempo de nossas vidas na escola - não só nós, professores - devemos ser felizes nela. A felicidade na escola não é uma questão de opção metodológica ou ideológica, mas sim uma obrigação essencial dela. Como diz Georges Snyders (1998) no livro A alegria na escola, precisamos de uma nova "cultura da satisfação", precisamos da "alegria cultural". O mundo de hoje é "favorável à satisfação" e a escola também pode sê-lo.

O que é ser professor hoje? Ser professor hoje é viver intensamente o seu tempo, conviver; é ter consciência e sensibilidade. Não se pode imaginar um futuro para a humanidade sem educadores, assim como não se pode pensar num futuro sem poetas e filósofos. Os educadores, numa visão emancipadora, não só transformam a informação em conhecimento e em consciência crítica, mas também formam pessoas. Diante dos falsos pregadores da palavra, dos marketeiros, eles são os verdadeiros "amantes da sabedoria", os filósofos de que nos falava Sócrates. Eles fazem fluir o saber (não o dado, a informação e o puro conhecimento), porque constróem sentido para a vida das pessoas e para a humanidade e buscam, juntos, um mundo mais justo, mas produtivo e mais saudável para todos. Por isso eles são imprescindíveis.

\section{PARA PENSAR A EDUCAÇÃO DO FUTURO}

Jacques Delors (1998), coordenador do "Relatório para a Unesco da Comissão Internacional Sobre Educação para o Século XXI", no livro Educação: um tesouro a descobrir, aponta como principal conseqüência da sociedade do conhecimento a necessidade de uma aprendizagem ao longo de toda a vida (Lifelong Learning) fundada em quatro pilares que são ao mesmo tempo pilares do conhecimento e da formação continuada. Esses pilares podem ser tomados também como bússola para nos orientar rumo ao futuro da educação.

Aprender a conhecer - Prazer de compreender, descobrir, construir e reconstruir o conhecimento, curiosidade, autonomia, atenção. Inútil tentar conhecer tudo. Isso supõe uma cultura geral, o que não prejudica o domínio de certos assuntos especializados. Aprender a conhecer é mais do que aprender a aprender. Aprender mais linguagens e metodologias do que conteúdos, pois estes envelhecem rapidamente. Não basta aprender a conhecer. É preciso aprender a pensar, a pensar a realidade e não apenas "pensar pensamentos", pensar o já dito, o já feito, reproduzir o pensamento. É preciso pensar também o novo, reinventar o pensar, pensar e reinventar o futuro.

Aprender a fazer - É indissociável do aprender a conhecer. A substituição de certas atividades humanas por máquinas acentuou o caráter cognitivo do fazer. O fazer deixou de ser puramente instrumental. Nesse sentido, vale mais hoje a competência pessoal que torna a pessoa apta a enfrentar novas situações de emprego, mas apta a trabalhar em equipe, do que a pura qualificação profissional. Hoje, o importante na formação do trabalhador, também do trabalhador em educação, é saber trabalhar coletivamente, ter iniciativa, gostar do risco, ter intuição, saber comunicar-se, saber resolver conflitos, ter estabilidade emocional. Essas são, acima de tudo, qualidades humanas que se manifestam nas relações interpessoais mantidas no trabalho. A flexibilidade é essencial. Existem hoje perto de 11 mil funções na sociedade contra aproximadamente 60 profissões oferecidas pelas universidades. Como as profissões evoluem muito rapidamente, não basta preparar-se profissionalmente para um trabalho.

Aprender a viver juntos - a viver com os outros. Compreender o outro, desenvolver a percepção da interdependência, da não-violência, administrar conflitos. Descobrir o outro, participar em projetos comuns. Ter prazer no esforço comum. Participar de projetos de cooperação. Essa é a tendência. No Brasil, como exemplo desta tendência, pode-se citar a inclusão de temas/eixos transversais (ética, ecologia, cidadania, saúde, diversidade cultural) nos Parâmetros Curriculares Nacionais, que exigem equipes interdisciplinares e trabalho em projetos comuns. 
Aprender a ser - Desenvolvimento integral da pessoa: inteligência, sensibilidade, sentido ético e estético, responsabilidade pessoal, espiritualidade, pensamento autônomo e crítico, imaginação, criatividade, iniciativa. Para isso não se deve negligenciar nenhuma das potencialidades de cada indivíduo. A aprendizagem não pode ser apenas lógico-matemática e lingüística. Precisa ser integral.

Iniciou-se este texto procurando situar o que significa "perspectiva". Sem pretender fazer qualquer exercício de futurologia e muito mais no sentido de estabelecer pontos para o debate, serão apontados aqui algumas categorias em torno da educação do futuro, que indicam o surgimento de temas com importantes consequiências para a educação.

As categorias "contradição", "determinação", "reprodução", "mudança", "trabalho", "práxis", "necessidade”, "possibilidade" aparecem freqüentemente na literatura pedagógica contemporânea, sinalizando já uma perspectiva da educação, a perspectiva da pedagogia da práxis. Essas categorias tornaram-se clássicas na explicação do fenômeno da educação, principalmente a partir de Hegel e de Marx. A dialética constitui-se, até hoje, no paradigma mais consistente para analisar o fenômeno da educação. Pode-se e deve-se estudá-la e estudar todas as categorias anteriormente apontadas. Elas não podem ser negadas, pois ajudarão muito na leitura do mundo da educação atual. Elas não podem ser negadas ou desprezadas como categorias "ultrapassadas". Porém, também podemos nos ocupar mais especificamente de outras, ao pensar a educação do futuro, categorias nascidas ao mesmo tempo da prática da educação e da reflexão sobre ela. Eis algumas delas a título de exemplo.

Cidadania - O que implica também tratar do tema da $a u$ tonomia da escola, de seu projeto político-pedagógico, da questão da participação, da educação para a cidadania. Dentro desta categoria, pode-se discutir particularmente o significado da concepção de escola cidadã e de suas diferentes práticas. Educar para a cidadania ativa tornou-se hoje projeto e programa de muitas escolas e de sistemas educacionais.

Planetaridade - A Terra é um "novo paradigma" (Leonardo Boff). Que implicações tem essa visão de mundo sobre a educação? O que seria uma ecopedagogia (Francisco Gutiérrez) e uma ecoformação (Gaston Pineau)? O tema da cidadania planetária pode ser discutido a partir desta categoria. Podemos nos perguntar como Milton Nascimento: "para que passaporte se fazemos parte de uma única nação?" Que conseqüências podemos tirar para alunos, professores e currículos?

Sustentabilidade - O tema da sustentabilidade originou-se na economia ("desenvolvimento sustentável") e na ecologia, para se inserir definitivamente no campo da educação, sintetizada no lema "uma educação sustentável para a sobrevivência do planeta”. O que seria uma cultura da sustentabilidade? Esse tema deverá dominar muitos debates educativos das próximas décadas. O que estamos estudando nas escolas? Não estaremos construindo uma ciência e uma cultura que servem para a degradação/deterioração do planeta?

Virtualidade - Esse tema implica toda a discussão atual sobre a educação a distância e o uso dos computadores nas escolas (Internet). A informática, associada à telefonia, nos inseriu definitivamente na era da informação. Quais as conseqüências para a educação, para a escola, para a formação do professor e para a aprendizagem? Conseqüências da obsolescência do conhecimento. Como fica a escola diante da pluralidade dos meios de comunicação? Eles abrem os novos espaços da formação ou irão substituir a escola?

Globalização - O processo da globalização está mudando a política, a economia, a cultura, a história e, portanto, também a educação. É um tema que deve ser enfocado sob vários prismas. A globalização remete também ao poder local e às conseqüências locais da nossa dívida externa global (e dívida interna também, a ela associada). O global e o local se fundem numa nova realidade: o "glocal". O estudo desta categoria remete à necessária discussão do papel dos municípios e do "regime de colaboração" entre União, estados, municípios e comunidade, nas perspectivas atuais da educação básica. Para pensar a educação do futuro, é necessário refletir sobre o processo de globalização da economia, da cultura e das comunicações.

Transdisciplinaridade - Embora com significados distintos, certas categorias como transculturalidade, transversalidade, multiculturalidade e outras como complexidade e holismo também indicam uma nova tendência na educação que será preciso analisar. Como construir interdisciplinarmente o projeto pedagógico da escola? Como relacionar multiculturalidade e currículo? É necessário realizar o debate dos PCN. Como trabalhar com os "temas transversais"? O desafio de uma educação sem discriminação étnica, cultural, de gênero. 
Dialogicidade, dialeticidade - Não se pode negar a atualidade de certas categorias freireanas e marxistas, a validade de uma pedagogia dialógica ou da práxis. Marx, em $O$ capital, privilegiou as categorias hegelianas "determinação", "contradição", "necessidade" e "possibilidade". A fenomenologia hegeliana continua inspirando nossa educação e deverá atravessar o milênio. A educação popular e a pedagogia da práxis deverão continuar como paradigmas válidos para além do ano 2000.

A análise dessas categorias e a identificação da sua presença na pedagogia contemporânea podem constituir-se, sem dúvida, num grande programa a ser desenvolvido hoje em torno das "perspectivas atuais da educação". Não se pretende aqui dar respostas definitivas. Com esse pequeno texto introdutório, procurou-se apenas iniciar um debate sobre as perspetivas atuais da educação, sem a inten- ção de, com isso, encerrá-lo. Existem muitos outros desafios para a educação. A reflexão crítica não basta, como também não basta a prática sem a reflexão sobre ela. Aqui, são indicadas apenas algumas pistas, dentro de uma visão otimista e crítica - não pessimista e ingênua - para uma análise em profundidade daqueles que se interessam por uma "educação voltada para o futuro", como dizia o grande educador polonês, o marxista Bogdan Suchodolski.

\section{REFERÊNCIAS BIBLIOGRÁFICAS}

DELORS, J. Educação: um tesouro a descobrir. São Paulo, Cortez, 1998. DOWBOR, L. A reprodução social. São Paulo, Vozes, 1998.

GADOtTI, M. Perspectivas atuais da educação. Porto Alegre, Ed. Artes Médicas, 2000.

SNYDERS, G. A alegria na escola. São Paulo, Ed. Manole, 1988. 